\title{
Atmospheric recirculation on the east coast of Gran Canaria Island
}

\author{
N. Pérez ${ }^{1}$, G. Rodríguez ${ }^{1} \&$ J. M. Pacheco ${ }^{2}$ \\ ${ }^{1}$ Departamento de Física, \\ Universidad de Las Palmas de Gran Canaria, Spain \\ ${ }^{2}$ Departamento de Matemáticas, \\ Universidad de Las Palmas de Gran Canaria, Spain
}

\begin{abstract}
A preliminary statistical study on the meteorological conditions governing the air quality, in terms of atmospheric recirculation, ventilation, and stagnation, on the east coast of Gran Canaria Island, a generally well-ventilated area, is presented. The study is based on the use of an objective methodology using single-station long-term time series of surface wind velocity. It is shown that, although during long periods, dominant wind conditions lead to substantial renovation of air masses at the study area, there exists a statistically significant probability of extreme events of recirculation which facilitate conditions for air pollutant accumulation, with eventual severe impacts on air quality. The frequency of occurrence of high recirculation factors presents a clear annual pattern reaching its maximum in winter.
\end{abstract}

Keywords: low atmosphere coastal circulation, atmospheric recirculation, ventilation and stagnation, pollutant transport modelling.

\section{Introduction}

Today, coastal areas depict a very complex scene. In addition to its intricate dynamic behaviour, due to its role as unique interface among sea, land, and atmosphere, the ever growing impact of anthropogenic activities is an added variable whose importance becomes more and more evident, therefore deserving a detailed study of the corresponding interaction networks. Indeed, population growth and the changes induced by newer coastal usages derived from the various economic activities related with it play an important role in the quality of 
coastal atmospheres as well. A number of spatial and temporal scales are involved in coastal atmospheric processes, and all of them must be taken into account in any analysis of pollution issues and their influence on coastal usage.

As a rule, the most common pollution sources for the atmospheric component are heavy traffic in coastal roads and industrial activities, usually oil refining or energy-generating facilities. They are responsible for a loss of air quality due to local high concentrations of gases, aerosols, and other particulate substances affecting both human health and environmental amenities [1, 2]. In the Canary Islands, a direct relationship has been observed between the exposure time to high concentrations of $\mathrm{SO}_{2}, \mathrm{NO}_{2}$, particulate matter, and the daily mortality rate of patients suffering from respiratory and blood circulation insufficiencies [3].

Pollutants may remain in the emission area, but they usually undergo some type of transport at various spatial and temporal scales, depending on topography, coastal morphology, deposition processes, chemical stability, and above all, on the local atmospheric conditions, where a thorough knowledge of wind intensity and direction may determine future management policies for pollutant emissions and their impact areas.

The main wind feature in coastal areas, the daily breeze oscillation, is a natural mixing and diluting agent at a local scale, but it may be superseded by larger scale phenomena [4]. For instance, long term stability periods normally associated to anticyclonic atmospheric behaviour give rise to conflictive episodes in heavily populated and potentially polluted coastal areas. On the other hand, turbulent atmospheres generally foster a cleaner air

The climate of the Canary Islands is the result of the relative intensity and location of the high pressure oceanic system known as the Azores High, as well as the conflict between this and the thermal low pressure centre over the Sahara. As a result, it is dominated by a quasi semi-annual presence of North-East trade winds, interspersed with short episodes where warm southerly or easterly winds from the Sahara bring dust all over the Islands. With this climate, coastal areas are usually under the action of rather strong winds contributing to rapid ventilation and preventing atmospheric pollution to become a problematic issue. Nevertheless, recirculation and stagnation may occur when the larger scale wind regime weakens and breezes dominate coastal atmospheric circulation. Consequently, the existence of time varying local flows requires us to study insitu air pollution regimes.

This study presents a statistical approach to the characterisation of stagnation, ventilation and recirculation episodes in the eastern coast of Gran Canaria. From the urban viewpoint, this area supports a six-lane highway all along the coastline, a huge airport, desalination and electricity generation thermal power plants, as well as most of the industrial facilities in the island. The database of wind speed and direction is the one provided by the airport meteorological station, covering the eight-year period (2004-2011). The methodological approach of Allwine and Whiteman [5] has been applied throughout, under the hypothesis of a homogeneous horizontal wind field over the study area. 


\section{Study area, data and methods}

\subsection{Study area}

The Canary Islands are close to the western coast of Africa. They are centred at the coordinates $\left(28^{\circ} \mathrm{N}, 15^{\circ} \mathrm{E}\right)$, its shortest distance to Africa being some $100 \mathrm{~km}$, measured from the easternmost island Fuerteventura. Their overall climate is clearly defined: The average atmospheric pressure in January is dominated by two more or less stationary North Atlantic anticyclonic vortices located between the islands and the Azores Archipelago and two others over Northeast Africa and the south of the Iberian Peninsula. By the beginning of April, the vortex closest to the Canaries gradually disappears, and the same happens with the African and Iberian high pressure areas. By July, a well defined Azores High and a Saharian Low dominate the scene. The Azores High weakens by September and the second High, closer to the Canaries, appears again in October-November, thus closing the annual cycle.

The above described oscillations in the location of the various high pressure areas determine the wind regime in the Canaries. In January, the northern boundary of the trade wind belt is just north of the islands, and NE trade winds blow with a frequency over $50 \%$. Later, that boundary travels northwards, so a pure trade wind regime reigns, with frequencies between $90 \%$ and $95 \%$ in the period of its northernmost location, usually in June. See Fig. 1 for the wind rose
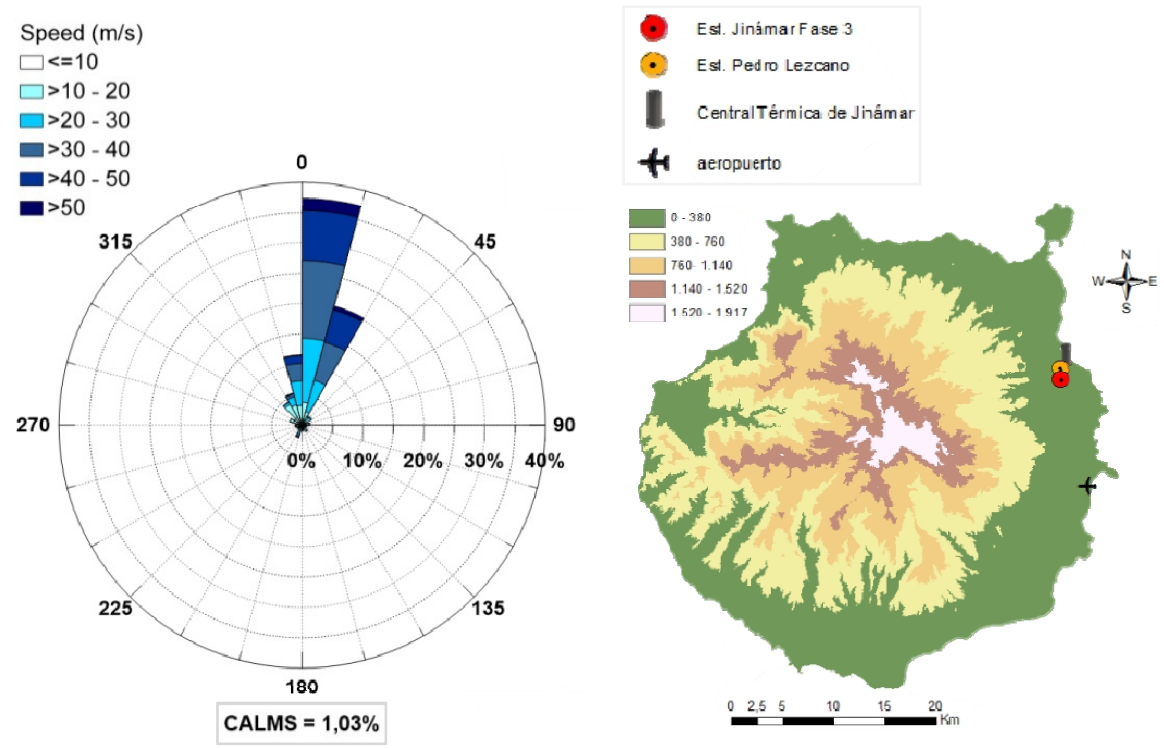

Figure 1: Wind rose for the complete study period (2004-2011) at the Airport of Gran Canaria (a). Topography of the island including location of the meteorological measurement and Jinámar thermal power stations (b). 
for the years 2004-2011. During the trade wind episodes in this period, the eastern coast of Gran Canaria received N-NE winds with a frequency over $60 \%$, during which windward cloud coverage was observed, while leeward clear skies were the rule. These conditions are common in summer: over $90 \%$ summer days follow this pattern. They are not so frequent in winter, but they are more common than any other weather regimes. Sometimes in winter anticyclonic ESE Saharan winds are observed at high altitudes, and they may coexist with a trade wind field at low altitudes [6].

The study area is the eastern coast of Gran Canaria. It has been chosen because the main pollution emitter in the island, the Central Térmica de Jinámar (28 $02^{\prime} 34^{\prime \prime}$; $\left.15^{\circ} 24^{\prime} 40^{\prime \prime}\right)$ is located in it, halfway between Las Palmas and the airport (see Fig. 1). This installation provides $50 \mathrm{MW}$ of energy through heavy fuel combustion, and its exhaust fumes contain dangerous amounts of $\mathrm{CO}_{2}, \mathrm{~N}_{2} \mathrm{O}$, $\mathrm{CH}_{4}, \mathrm{NOx}, \mathrm{SOx}, \mathrm{Ni}, \mathrm{Zn}$ and $\mathrm{PM}_{10}$. About half of the island population resides within 10 to $15 \mathrm{~km}$ of the power plant, in the urban areas of Las Palmas and Telde.

\subsection{Data}

To characterize the atmospheric circulation in terms of stagnation, recirculation and ventilation, air mass, records of intensity and direction of the horizontal wind obtained by the Meteorological Agency at the airport of Gran Canaria (GC) $\left(28^{\circ} 05^{\prime} 23^{\prime \prime} \mathrm{N}, 15^{\circ} 23^{\prime} 22^{\prime \prime} \mathrm{W}\right)$, for its proximity to the power station, as well as the quality and length of the series of recorded data.

The study period comprises 8 years, between January 2004 and December 2011 , during which the percentage of valid data module and direction of the wind speed is in all cases greater than 98\%. They have been chosen because these years are the most recent, are hourly measurements and match the contaminant data to be used in subsequent studies.

\subsection{Methodology}

The potential wind transport capacity over a certain area and for some specified period may be assessed through the methodology proposed by Allwine and Whiteman [5]. They introduce three parameters to evaluate or describe atmospheric circulation at the local scale, employing a single measuring station for wind direction and velocity, under the hypothesis of a homogeneous surface wind field. This approach permits to estimate the displacement of air parcels by assuming that wind velocity remains steady over considerable time-space scales (i.e., $[7,8]$ ), thus removing the need for a large number of large and spatially distributed data sets, which are no commonly available.

The chosen integral parameters can be conceptually understood as follows: Stagnation, corresponding to episodes where wind intensity decreases, thus favouring pollutant accumulation near its source; Ventilation describes events during which clean air replace polluted air, and Recirculation episodes are those where polluted air masses initially fly away from the source, but the reigning 
wind conditions drive them back to the source neighbourhood, where pollutants accumulate, thus yielding higher undesirable concentrations.

For $\mathrm{N}$ pairs $\left(\mathrm{V}_{\mathrm{i}} ; \theta_{\mathrm{i}}\right)_{\mathrm{i}}={ }_{1, \ldots, \mathrm{N}}$, (wind intensity, wind direction), where direction is measured clockwise from the North $\left(0^{\circ} \equiv 360^{\circ}\right)$ the components of the horizontal wind speed East-West (positive towards East), u, and North-South (positive towards North), v, may be expressed as follows:

$$
\begin{aligned}
& \mathrm{u}_{\mathrm{i}}=\mathrm{V}_{\mathrm{i}} \sin \left(\theta_{\mathrm{i}}-180\right) \\
& \mathrm{v}_{\mathrm{i}}=\mathrm{V}_{\mathrm{i}} \cos \left(\theta_{\mathrm{i}}-180\right)
\end{aligned}
$$

$t_{i}$ is the observation time, measured as

$$
\mathrm{t}_{\mathrm{i}}=\mathrm{t}_{0}+(\mathrm{i}-1) \Delta \mathrm{t}
$$

where $t_{0}$ is the initial observation time and $\Delta t$ represents the interval between samples.

The distance travelled by an air parcel may be estimated after the above expressions for the zonal and meridional components. After a time period $\tau$, the coordinates of the air parcel will be,

$$
\begin{aligned}
& X_{i \tau}=\Delta \mathrm{t} \sum_{j=i}^{i+\tau-1} u_{j} \\
& Y_{i \tau}=\Delta \mathrm{t} \sum_{j=i}^{i+\tau-1} v_{j}
\end{aligned}
$$

For this study, $\tau=24 \mathrm{~h}$ and $\Delta \mathrm{t}=1 \mathrm{~h}$. The net displacement or resulting transport distance will be:

$$
L_{i \tau}=\Delta \mathrm{t} \sqrt{X_{i \tau}^{2}+Y_{i \tau}^{2}}
$$

The total wind displacement is:

$$
S_{i \tau}=\Delta \mathrm{t} \sum_{j=i}^{i+\tau-1} V_{j}
$$

The recirculation factor, whose value range lies between 0 and 1 , is defined as:

$$
R_{i \tau}=1-\frac{L_{i \tau}}{S_{i \tau}}
$$

In other words, the resulting transport distance is larger than the net wind displacement. Equality of $\mathrm{S}_{\mathrm{i} \tau}$ and $\mathrm{L}_{\mathrm{i} \tau}$ happens in the case of a purely unidirectional wind flow

The stagnation parameter $S_{i \tau}$ depends basically on wind intensity, while the recirculation one $\mathrm{R}$ is dependent on wind direction changes. Therefore, when the wind direction persists, $\mathrm{L}_{\mathrm{i} \tau}$ and $\mathrm{S}_{\mathrm{i} \tau}$ have close values, its ratio approaches 1 and 
the recirculation factor tends to 0 . Then ventilation occurs with a continuous renewal of air masses. On the other hand, when the wind direction is highly variable, net transport diminishes. If the difference between $\mathrm{L}_{\mathrm{i} \tau}$ and $\mathrm{S}_{\mathrm{i} \tau}$ is large, $\mathrm{R}$ approaches 1, and the polluted air parcel returns to the source neighbourhood. Previous situations are schematically depicted in Fig. 2. Note that when $S_{i \tau}$ equals 0 , stagnation occurs, describing the case of very slow winds or, strictly, calm episodes. The mathematical singularity occurring in such case is removed by equating $\mathrm{R}$ to zero.
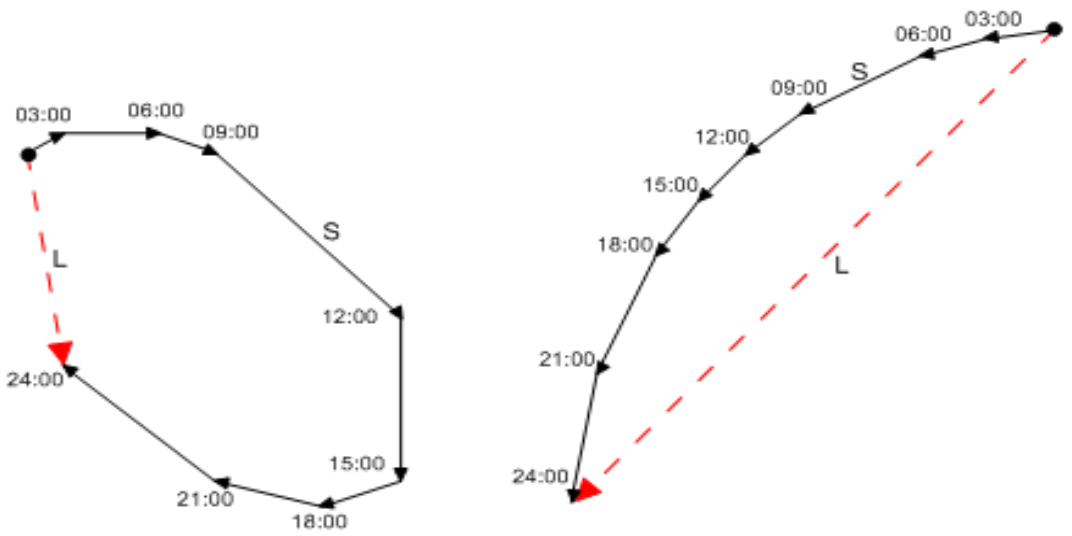

Figure 2: Relationship between net displacement, L, and total wind displacement, S, for cases of intense (a) and weak (b) recirculation.

\section{Results and discussion}

The time series of recirculation factor daily values is shown in Fig. 3, for the entire study period. The existence of a clear, although variable, seasonal pattern, as well as considerable interannual variations, result evident from this figure. In general, recirculation values are larger during winter and significantly decreases in summer. Nevertheless, it is possible to appreciate the existence of some episodic events with relatively high values of $\mathrm{R}$ during summer.

The empirical probability density functions of the three integral parameters have been estimated to quantify the relative frequency of occurrence of ventilation, stagnation, and recirculation episodes. These empirical distributions have been derived by using a kernel density estimation approach, with a Gauss density as kernel function and a data adaptive optimal bandwidth selection criterion. Associated $95 \%$ confidence intervals have been estimated by applying a nonparametric bootstrapping procedure to generate 1000 replicates.

Net displacement, L, and wind run, S, probabilistic densities (not shown) present a similar shape, especially in the range of intermediate and high values. However, differences are notable for low values of both variables. This fact indicates the existence of long periods of time during which the study area is well ventilated, with high and similar values $\mathrm{S}$ and $\mathrm{L}$, while significant 
differences between both parameters give rise to short episodes of intense recirculation, such as can be inferred from empirical density function of the recirculation factor shown in Fig. 4. The high probability of environmental conditions associated with low values of $\mathrm{R}$ demonstrates the dominance of the ventilation conditions in the study area. Nevertheless, the heavy tail of this distribution clearly points to the existence of extreme recirculation events. These episodes with low frequency of occurrence may have severe impacts on air quality and cannot be disregarded, although their duration is commonly short, such as observed in Fig. 3.

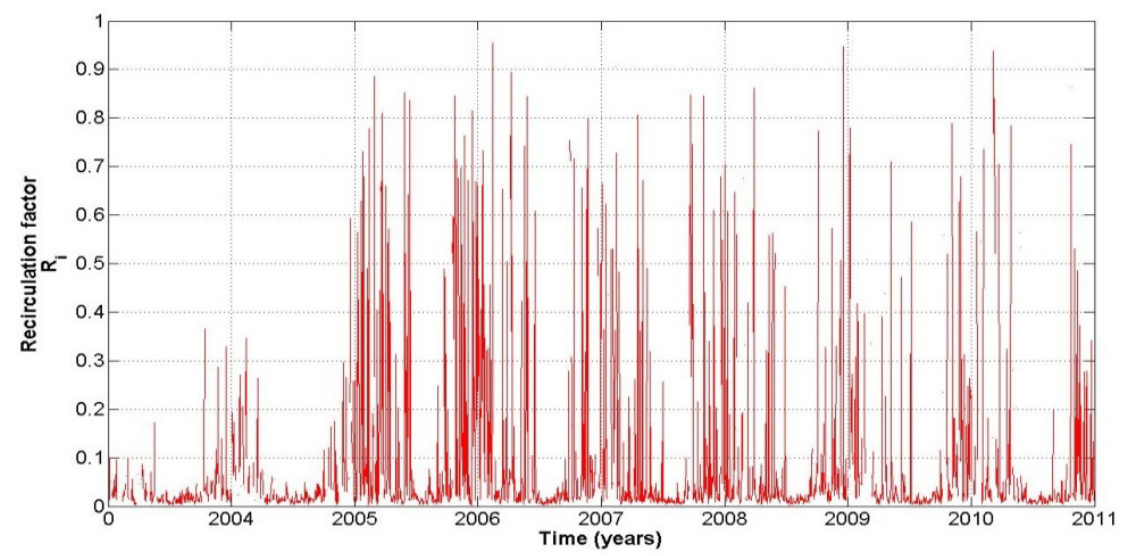

Figure 3: Time evolution of the recirculation factor at the study area for the period 2004-2011.

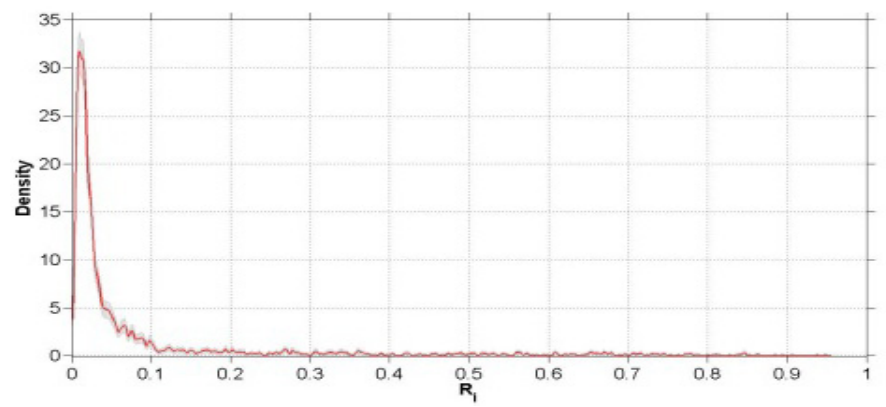

Figure 4: Empirical density functions probability of net displacement, wind run and recirculation factor in the Gran Canaria Airport.

A yearly analysis of $\mathrm{R}, \mathrm{L}$ and $\mathrm{S}$ probability density functions (not shown) reveals a considerable temporal variability of their probabilistic structure. This analysis clearly reflect the low number of recirculation events occurred during the first two years and its increase during the following years, especially in 2006, 
in which the first, second (median) and third quartiles reach the higher observed values for $\mathrm{R}$ and therefore the lower values of net displacement.

A similar situation is observed when comparing the empirical distributions estimated for each climatic season. This procedure evidence a clear annual pattern in the frequency of occurrence of high recirculation factors. Thus, while in summer (Fig. 5a) the frequency of occurrence of factors above 0.1 is almost negligible, the likelihood of recirculation phenomena increases slightly in autumn and mainly during the spring, reaching its maximum in winter (Fig. 5b).

Thus, spring and autumn act as transitional periods between summer and winter conditions. It is worth to mention the significant increase of extreme recirculation events occurrence during winter.
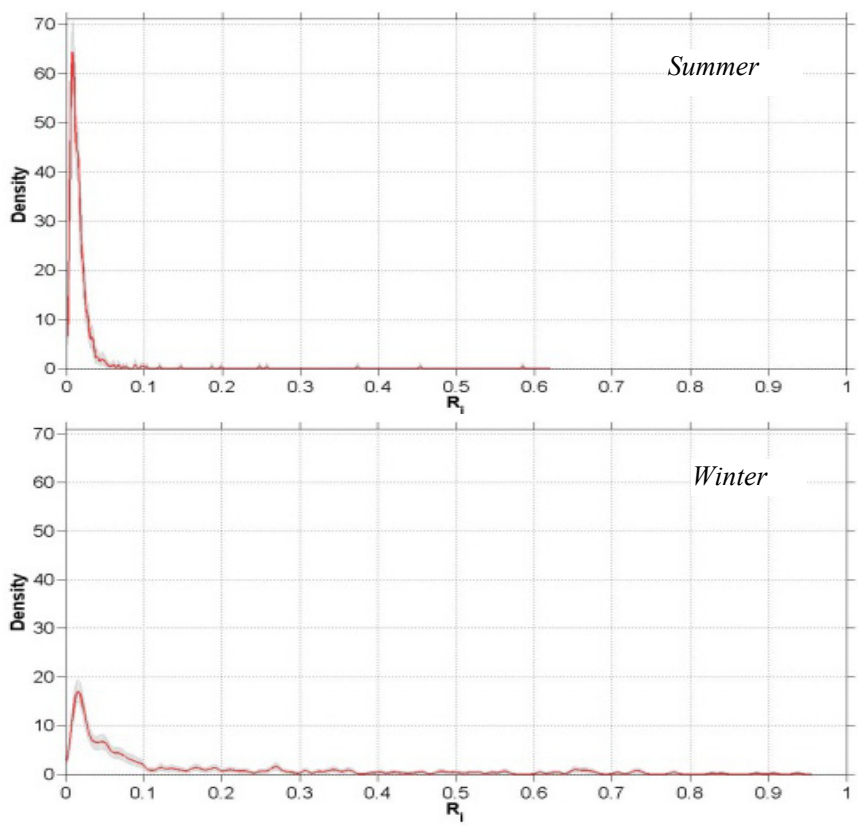

Figure 5: Recirculation factor empirical probability density functions for summer (upper) and winter (lower) seasons at Gran Canaria Airport.

The above commented seasonal variability in the frequency of occurrence of intense atmospheric recirculation episodes is a clear manifestation of the annual pattern of large scale flows affecting the study area, mainly modulated by the intensity and latitudinal migration of the Azores High. This fact becomes clear by jointly representing the synoptic average wind conditions over the Canary Islands area during summer and winter (Fig. 6, left and right upper panels) and the wind roses measured at Gran Canaria Airport during these seasons (Fig. 6, left and right lower panels). 
In both representations, the intensity and direction of the wind show a significant change between summer and winter. It is worth of mentioning the low directional variability observed during summer, with a frequency greater than $85 \%$ associated with winds from the N-NE sector. Furthermore, during this period wind speed frequently exceeds $30 \mathrm{~m} / \mathrm{s}$, reflecting the well-known predominance of the North-trade winds during summer. Conditions change substantially during winter, when the Azores high pressure center weakens and moves southward. Then, in general, a substantial increase in the directional variability and a noticeable drop in the intensities are observed. Under these conditions, the area experiences a greater number of conditions favoring the appearance of recirculation episodes while strong ventilation events decrease.

Consequently, during summer the study area is heavily ventilated and recirculation events are virtually nonexistent, with the exception of sporadic episodes, as shown in Fig. 3. With the arrival of spring the situation changes slightly, showing a slight increase in directional variability and a decrease in the intensity of the wind, even though the trade wind clearly continues to dominate the wind regime in the area. These slight changes in wind conditions result in slight decrease of ventilation conditions and increased recirculation events, as compared to the summer situation.
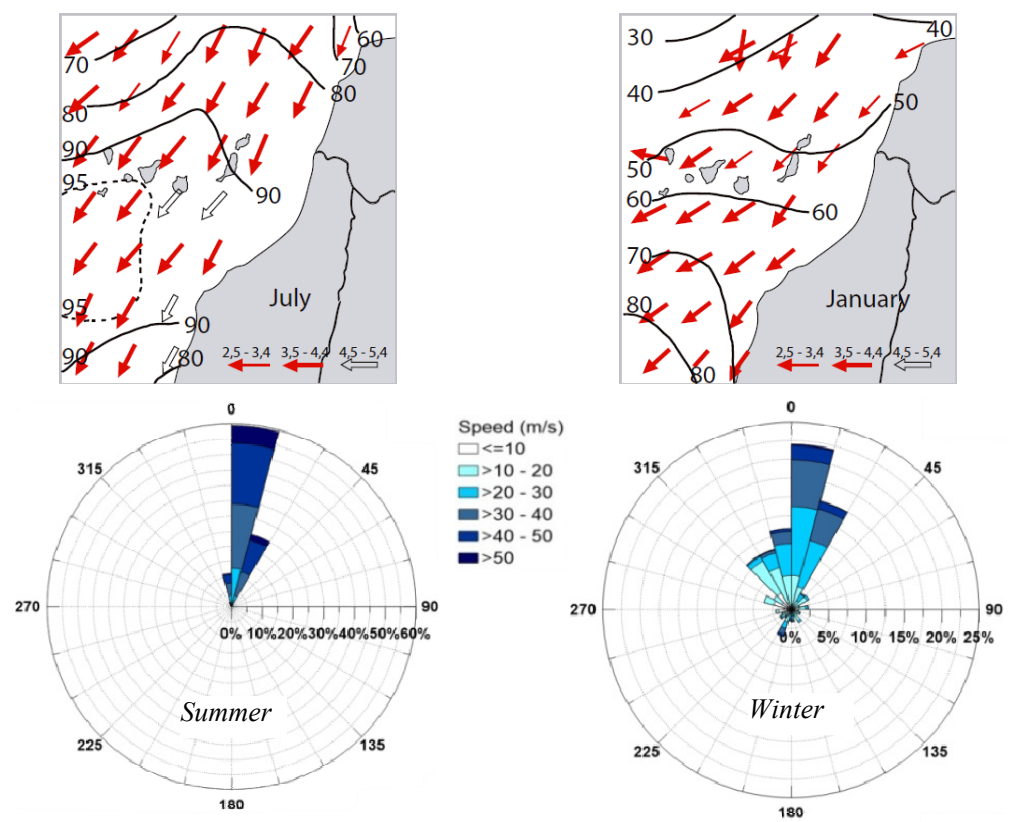

Figure 6: $\quad$ Prevailing wind conditions (adapted from Tullot 1956) over Canary Islands during July and January (upper panels), and wind roses for summer and winter (lower panels) at Gran Canaria Airport.

The above cited change of the ventilation and recirculation conditions according to the seasons is clearly reflected in Fig. 7, depicting the annual 
average of the daily recirculation factor values, $R_{\text {avg }}$ against its associated standard deviation, $\mathrm{R}_{\text {std. }}$. The color of each pair of values shown denotes the climatic season to which it corresponds. This figure reveals that, on average, recirculation factor reaches their lowest values during the summer period. Both the mean values of $\mathrm{R}$ and its variability increase during the transitional seasons, spring and fall, and reach their peak during the winter. On the contrary to the summer conditions, during the rest of the year, particularly in winter, $\mathrm{R}_{\mathrm{avg}}$ values cover a wide range, alternating episodes of recirculation with periods of ventilation predominance.

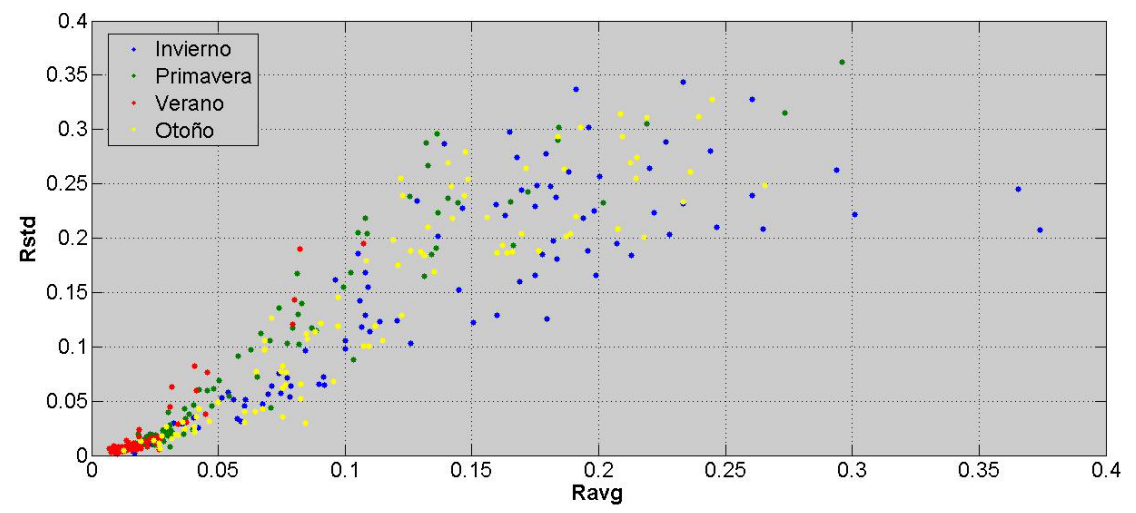

Figure 7: Average daily recirculation factor and its standard deviation for the different seasons in the Gran Canaria Airport, during the study period.

\section{Conclusions}

The intensity and persistence of the North-trade winds for much of the year, causes a substantial renovation of air masses at the east coast of Gran Canaria. Consequently, the area is, in general, well ventilated for long periods. Nevertheless, empirical probability density functions show significantly right heavy tail, thus highlighting the existence of extreme events of recirculation, mainly during winter, which facilitate conditions for air pollutant accumulation, with eventual severe impacts on air quality.

The seasonality of the prevailing synoptic wind field induces an annual pattern in recirculation and ventilation events. In summer, the area is heavily ventilated and recirculation events are practically nonexistent. In winter these situations change notably, with a significant increase of recirculation episodes, while spring and autumn represent transitional periods between these situations.

\section{Acknowledgement}

The authors would like to thank the Spanish Meteorological Agency (AEMET) for providing the wind dataset. 


\section{References}

[1] Ayres, J.G., Maynard, R.L., Richards, R., (2006). Air Pollution and Health, IPC, Imperial College Press.

[2] Khallaf, M.K., (2011). The Impact of Air Pollution on Health, Economy, Environment and Agricultural Sources, InTech.

[3] López-Villarrubia, E., Iñiguez, C., Peral, N., García, M., Ballester, F., (2012). Characterizing mortality effects of particulate matter size fractions in the two capital cities of the Canary Islands, Env. Res., 112, 129-138.

[4] Hsu, S.A., (1988). Coastal Meteorology. Academic Press, 260 pp.

[5] Allwine, K.J., Whiteman, C.D., (1994). Single-station integral measures of atmospheric stagnation, recirculation and ventilation, Atm. Env., 28(4), 713721.

[6] Font Tullot, I., (1956). El tiempo atmosférico en las islas Canarias, (Madrid, Servicio Meteorológico Nacional) Pub. ser. A26 (in Spanish).

[7] Kumar, D., Kumar A., Kumar, V., Kumar, J., Ravi, P.M., (2012). Study of atmospheric stagnation, recirculation and ventilation potential at Narora Atomic Power Station NPP site. Env. Monit. Asses., doi: 10.1007/s10661.

[8] Levy, I., Dayan, U., Mahrer, Y., (2008). A five-year study of coastal recirculation and its effect on air pollutants over the East Mediterranean region. J. Geophys. Res., 113, D16121, doi: 10.1029/2007JD009529. 